\title{
Use of Melatonin for Sleep Disorders in Children with Cerebral Palsy Domenico M Romeo ${ }^{1 *}$, Giorgia Olivieri ${ }^{1}$ and Claudia Brogna ${ }^{1,2}$ \\ ${ }^{1}$ Pediatric Neurology Unit, Catholic University, Rome, Italy \\ 2Unit of Child and Adolescent NeuroPsychiatry, Laboratory of Molecular Psychiatry and Neurogenetics, University "Campus Bio-Medico", Rome, Italy
}

\begin{abstract}
Sleep disorders are more frequent in in children with Cerebral Palsy than in typically developing children. Although no sleep interventions or trials specifically designed for sleep disorders in children with CP are reported in the literature, the use of melatonin has been proposed in improving sleep quality in these patients.
\end{abstract}

Keywords: Sleep disorders; Cerebral palsy; Melatonin

\section{Opinion}

Cerebral Palsy (CP) is a group of disorders of movement and posture caused by a non-progressive interference, lesion or abnormality of the immature brain which is often accompanied by impairment of sensation, cognition and communication and affecting more than 2 per 1000 live-born children [1]. Sleep disorders are more frequent in $\mathrm{CP}$ than in typically developing children with a prevalence varying from 19 to $63 \%$ according to different studies. Different feature such as motor or cognitive impairment, behavioral problems or epilepsy are important risk factors for the development of sleep disorders. [2-4]. No specific studies on sleep intervention for children with CP are reported in literature [2] even if a good "sleep hygiene", parentbased education and behavioural interventions [2], should be adopted before beginning a specific therapy. Melatonin ( $\mathrm{N}$-acetyl-5methoxytryptamine), a tryptophan-derived molecule, is a chronobiotic drug produced by the pineal gland essential for the regulation of the sleep-wake cycle. During the day, the synthesis of melatonin is limited, being the concentrations peaking at approximately midnight, due to the liberation of norepinephrine through the beta-adrenergic receptors in the pinealocytes $[2,5]$. Melatonin has been mainly used in circadian rhythm disorders in adults such as sleep disturbances, jet lag, sleepwake cycle disturbances in blind people and shift workers. Recently it has been proposed in children with sleep disturbances confirming its role in improving sleep [2,5]. It is considered safe and well tolerated with a long term effectiveness in improving sleep $[2,5]$.

Few studies reported results on the use of melatonin in children with neurodevelopmental disabilities (ND) including CP patients, even if not exclusively [6-13]. In these studies melatonin has been administered 30-60 minutes before the child's usual bedtime with a dose ranging from 0.5 to $12 \mathrm{mg}$ for a period $>4$ weeks, showing an effect in both reducing the time to sleep onset or sleep latency and increasing the total duration of continuous sleep throughout the night. The authors did not mention significant adverse side effects even if two possible severe adverse effects should be reported on the later puberty and on seizures. Melatonin may play a role in physiological development of normal puberty, due to the presence of melatonin receptors in the adrenal glands and ovaries; melatonin could be responsible of a delay pubertal development in some children after a long term melatonin treatment and at high dosage inhibiting the gonadotropin-releasing hormone from the hypothalamus, necessary for secretion of the anterior pituitary hormones (gonadotropic hormones luteinizing hormone and follicle stimulating hormone) [14].

It is well known that a better quality of sleep improve seizures control in children; different studies confirmed that low dose of melatonin treatment reduced the number of seizures in children with uncontrolled epilepsy (2). However in a limited number of cases of severe neurologically disabled children melatonin can potentially increase seizure activity [11]; therefore there is some discussion on whether its use should be limited in children with $\mathrm{CP}$ associated with active epilepsy [13]. The studies reported in the literature have some methodological limitations, as the inclusion of heterogeneous ND children with different specific patterns of sleep problems, a relatively small size population and the use of different methods of recording sleep and sleep-wake patterns (questionnaires or diaries and actigraphy). In our clinical experience melatonin has been used in children with $\mathrm{CP}$ with different motor impairment and sleep disorders, assessed using questionnaires and diaries completed by parents and when possible by children itself. We observed an improvement of quality and quantity of sleep in most of cases, especially in sleep latency and night time sleep duration, with no side effects even in those children with active epilepsy.

The use of Melatonin in children with $\mathrm{CP}$ is promising even if not yet conclusive; it remains a commonly prescribed medication for disturbed sleep in these population of children not only for the wellbeing of the child but, notably, also for the well-being of the family (2). Additional researches with large multicentre randomized placebocontrolled trial are need to determine whether there is real benefit from the use of melatonin in children with $\mathrm{CP}$, on both sleep-latency and on total sleep time including possible adverse effects on seizures and endocrine functions.

\section{References}

1. Morris C (2007) The definition and classification of cerebral palsy. Dev Med Child Neurol Suppl 109: 3-7.

2. Angriman M, Caravale B, Novelli L, Ferri R, Bruni O (2015) Sleep in children with neurodevelopmental disabilities. Neuropediatrics 46: 199-210.

3. Newman CJ, O'Regan M, Hensey O (2006) Sleep disorders in children with cerebral palsy. Dev Med Child Neurol 48: 564-568.

4. Romeo DM, Brogna C, Quintiliani M, Baranello G, Pagliano E, et al. (2013) Sleep disorders in children with Cerebral Palsy: neurodevelopmental and behavioral correlates. Sleep Medicine 15: 213-218.

*Corresponding author: Domenico M. Romeo, Pediatric Neurology, Catholic University, Largo Gemelli 8, 00168 Rome, Italy, Tel: +390630155340, Fax: +390630154363; E-mail: domenicomarco.romeo@policlinicogemelli.it

Received December 21, 2015; Accepted December 23, 2015; Published December 29, 2015

Citation: Romeo DM, Olivieri G, Brogna C (2015) Use of Melatonin for Sleep Disorders in Children with Cerebral Palsy. Brain Disord Ther 4:201. doi:10.4172/2168-975X.1000201

Copyright: (c) 2015 Romeo DM, et al. This is an open-access article distributed under the terms of the Creative Commons Attribution License, which permits unrestricted use, distribution, and reproduction in any medium, provided the original author and source are credited. 
Citation: Romeo DM, Olivieri G, Brogna C (2015) Use of Melatonin for Sleep Disorders in Children with Cerebral Palsy. Brain Disord Ther 4:201. doi:10.4172/2168-975X.1000201

Page 2 of 2

5. Rios ER, Venâncio ET, Rocha NF, Woods DJ, Vasconcelos S, et al. (2010) Melatonin: pharmacological aspects and clinical trends. Int J Neurosci 120: 583-590.

6. Phillips L, Appleton RE (2004) Systematic review of melatonin treatment in children with neurodevelopmental disabilities and sleep impairment. Dev Med Child Neurol 46: 771-775

7. Wasdell MB, Jan JE, Bomben MM, Freeman RD, Rietveld WJ, et al. (2008) A randomized, placebo-controlled trial of controlled release melatonin treatment of delayed sleep phase syndrome and impaired sleep maintenance in children with neurodevelopmental disabilities. J Pineal Res 44: 57-64.

8. Dodge NN, Wilson GA (2001) Melatonin for treatment of sleep disorders in children with developmental disabilities. J Child Neurol 16: 581-584.

9. Ross C, Davies P, Whitehouse W (2002) Melatonin treatment for sleep disorders in children with neurodevelopmental disorders: an observational study. Dev Med Child Neurol 44: 339-344.

10. Appleton RE, Jones AP, Gamble C, Williamson PR, Wiggs L, et al. (2012) The use of Melatonin in children with neurodevelopmental disorders and impaired sleep: a randomised, double-blind, placebo-controlled, parallel study (MENDS). Health Technol Assess 16: i-239.

11. Sheldon SH (1998) Pro-convulsant effects of oral melatonin in neurologically disabled children. Lancet 351: 1254

12. Schwichtenberg AJ, Malow BA (2015) Melatonin Treatment in Children with Developmental Disabilities. Sleep Med Clin 10: 181-187.

13. Galland BC, Elder DE, Taylor BJ (2012) Interventions with a sleep outcome for children with cerebral palsy or a post-traumatic brain injury: a systematic review. Sleep Med Rev 16: 561-573.

14. Brzezinski A (1997) Melatonin in humans. N Engl J Med 336: 186-195. 